Documentación de las Ciencias de la Información ISSN: 0210-4210

https://doi.org/10.5209/dcin.63087

\title{
Documentación para el periodista especializado en arte: la importancia de las fuentes
}

\author{
Violeta Izquierdo Expósito; Marina Fernández Maestre²
}

Recibido: 29 de enero de 2019/ Aceptado: 25 de julio de 2019

Resumen. La presente investigación ofrece una panorámica del proceso de documentación básico para todo periodista dedicado profesionalmente al campo del periodismo especializado en arte. Tras estudiar los planes de estudio de las facultades de Periodismo españolas, y comprobar que tan solo la mitad de ellas imparten la asignatura de Periodismo Especializado y que solo un reducido número de ellas cuenta con optativas en materia de arte, se ha considerado necesario realizar un artículo que contenga las claves del proceso de documentación de este profesional. El objetivo final de esta investigación es desarrollar una metodología que el periodista pueda seguir durante el proceso de documentación previo a la elaboración de un texto especializado en contenidos artísticos.

Palabras Clave: Periodismo; Periodismo Especializado; Periodismo Cultural; Periodismo Especializado en Arte; Arte; Fuentes; Facultad de Periodismo; Plan de Estudios

\section{[en] Documentation for the Specialized Journalist in Arts: The Importance of the sources}

\begin{abstract}
The present research provides an overview of the basic documentation process in the field of arts journalism. After perusing the established curriculums in the Spanish Schools of Journalism and finding out that only half of them teach the subject of Specialized Journalism, and that, moreover, only a few offer elective courses in arts, we considered an article highlighting the best practices for documenting in arts journalism to be of the utmost importance. The final goal of this research is to develop a common methodological framework for optimizing artistic content in journalism.

Keywords. Journalism; Speacialized Journalism; Cultural Journalism; Specialized Journalism in Arts; Art; Sources; School of Journalism; Syllabus
\end{abstract}

Sumario: Introducción y objeto de la investigación; Metodología; Perfil del periodista especializado en arte; Fuentes para el periodismo especializado en arte; Conclusiones; Bibliografía

Cómo citar: Izquierdo Expósito, V.; Fernández Maestre, M. (2019). Documentación para el periodista especializado en arte: la importancia de las fuentes en Documentación de las Ciencias de la Información, 42, 105-115.

1 Facultad de Ciencias de la Información.

Universidad Complutense de Madrid

violeta.izquierdo@ccinf.ucm.es

2 Facultad de Ciencias de la Información.

Universidad Complutense de Madrid

marinf40@ucm.es 


\section{Introducción y objeto de la investigación}

La presente investigación está centrada en profundizar en la profesión del periodista especializado en arte definiendo, en primer lugar, su perfil y su cometido $\mathrm{y}$, en segundo lugar, aportando una serie de fuentes y recursos que le sirvan de ayuda en su práctica profesional, como freelance o como parte del equipo de redacción de un medio, sobre todo al inicio de su carrera. El Periodismo Especializado en Arte es una de las disciplinas (junto al Especializado en la Literatura, el Cine, las Artes Escénicas y la Música) que se inserta dentro del Periodismo Cultural, y este último es, a su vez, una de las grandes áreas temáticas del Periodismo Especializado.

El papel del periodista especializado dentro del sector es absolutamente relevante, ya que «la sobrecarga informativa ha hecho necesaria la labor de selección y tratamiento de los múltiples mensajes que llegan a las redacciones, presentándolos de forma ordenada y debidamente codificados» (Fernández del Moral y Estévez Ramírez 2010: 181). Una labor, que en las redacciones suelen desempeñar los profesionales que ya tienen varios años de experiencia, lo cual no implica, como en más de una ocasión se confunde, que todos los periodistas con experiencia sean periodistas especializados en una temática. No obstante, este estudio recoge las claves del proceso de documentación de un periodista especializado en arte para que aquel que tenga que elaborar por primera vez un texto especializado en dicha materia o quiera iniciarse en este campo, consiga profesionalizarse en el menor tiempo posible y alcanzar esos niveles de «eficiencia», que tanto demandan los medios, sin renunciar a la calidad de los contenidos. Porque si el periodismo especializado cuenta con un enemigo, ese es el factor inmediatez, que con los años ha aumentado de manera exponencial.

Como ya apuntaba Hector Borrat (1993: 80) hace más de dos décadas, en la actualidad se tiende cada vez más a renunciar a un periodismo especializado en favor de un periodismo de mayor alcance: «no es de extrañar que la concepción profesional del periodismo especializado encuentre su referente principal en el éxito comercial. El periodismo óptimo sería el que mejor se vende y el periodista modélico, el que más eficaz e incondicionalmente contribuye al lucro de la empresa para la cual trabaja. Como entre los grandes éxitos de venta no destaca precisamente el periodismo especializado, el periodismo óptimo seguiría siendo el periodismo común, y el periodista modélico seguiría siendo el generalista, al que se le reconoce la doble capacidad de representar el punto de vista del lector común, y de estar siempre dispuesto a adaptarse de manera inmediata a súbitos cambios de roles profesionales e incluso de medios».

\section{Metodología}

El punto de partida de esta investigación ha sido analizar de manera cualitativa y cuantitativa la formación recibida por los alumnos de las universidades españolas en las materias de Periodismo Especializado, en Periodismo Cultural y en Arte. Para ello, se han consultado los planes de estudio de todas las facultades, así como los contenidos de las guías docentes de cada asignatura. De esta primera parte hemos obtenido la Tabla 1 . 


\begin{tabular}{|l|c|}
\hline \multicolumn{1}{|c|}{ Facultades españolas } & Número \\
\hline Grados en Periodismo & 43 \\
\hline $\begin{array}{l}\text { Grados en Periodismo con la asignatura de Periodismo Especializado en el Plan } \\
\text { de Estudios como obligatoria }\end{array}$ & 22 \\
\hline $\begin{array}{l}\text { Grados en Periodismo con la asignatura de Periodismo Especializado en el Plan } \\
\text { de Estudios como optativa }\end{array}$ & 1 \\
\hline $\begin{array}{l}\text { Grados en Periodismo que tratan los contenidos culturales dentro de la asignatura } \\
\text { de Periodismo Especializado }\end{array}$ & 10 \\
\hline Grados en Periodismo con la asignatura de Periodismo Cultural como obligatoria & 0 \\
\hline Grados en Periodismo con la asignatura de Periodismo Cultural como optativa & 13 \\
\hline Grados en Periodismo con asignaturas obligatorias de Arte & 1 \\
\hline Grados en Periodismo con asignaturas optativas de Arte & 4 \\
\hline
\end{tabular}

Tabla 1. Datos del análisis de los Planes de Estudio del Grado en Periodismo de las Facultades españolas en relación al Periodismo Especializado, el Periodismo Cultural y las asignatura de Arte.

Los datos de la tabla muestran que la enseñanza del Periodismo Especializado en las universidades españolas no goza de buena salud. Tan solo veintitrés facultades, del total de las cuarenta y tres que ofertan actualmente el Grado en Periodismo, incluyen en su plan de estudios una asignatura dedicada a esta materia. Veintidós la tienen como obligatoria y una como optativa. Los resultados son aún peores si nos centramos solo en aquellas que tratan el área de Cultura dentro de los contenidos de esta asignatura. $\mathrm{Al}$ analizar las guías docentes hemos comprobado que son solo diez. El número de las que ofertan la asignatura de Periodismo Cultural tampoco es mucho mayor. Solo trece y siempre en la modalidad de optativa. En cuanto a las materias específicamente de Arte, el número de universidades que ofertan este tipo se reduce a cuatro, aunque sorprende gratamente ver como una de las facultades (la Universidad Europea Miguel de Cervantes de Valladolid) tiene una asignatura de Arte como obligatoria, como se detalla en la tabla 2.

Después de realizar este estudio, y comprobar que en algunas universidades la enseñanza del periodismo especializado en arte es nula, hemos procedido a desarrollar una investigación que defina el perfil de periodista especializado en arte y ofrezca una serie de claves básicas que le ayuden en el proceso de documentación, prestando especial énfasis a las fuentes.

\section{Perfil del periodista especializado en arte}

La función principal del periodista especializado responde a la «necesidad de abordar el conocimiento de manera sectorializada con herramientas que permiten el acceso a conocimientos que, de otra forma, estarían reservados a expertos» (López 2004: 385). Ahora bien, teniendo claro que «el periodismo especializado nace jus- 
tamente para hacer frente a la especialización en el conocimiento. Se trata, por el contrario, de hacer posible al periodismo su penetración en el mundo de la especialización, no para convertir a nuestros profesionales en falsos especialistas, no para obligar al periodismo a parcelarse, a subdividirse, sino al contrario: para hacer de cada especialidad algo comunicable, objeto de información periodística, susceptible de codificación para mensajes universales» (Fernández del Moral 2004: 24).

\begin{tabular}{|l|l|l|}
\hline \multirow{2}{*}{ Universidad Complutense de Madrid } & Arte español contemporáneo & Optativa \\
\cline { 2 - 3 } & Movimientos artísticos contemporáneos & Optativa \\
\hline $\begin{array}{l}\text { Universidad Europea Miguel de } \\
\text { Cervantes (Valladolid) }\end{array}$ & Movimientos Artísticos Contemporáneos & Obligatoria \\
\hline $\begin{array}{l}\text { CESINE Centro Universitario en } \\
\text { Santander }\end{array}$ & Movimientos artísticos contemporáneos & Optativa \\
\hline \multirow{2}{*}{ Universitat Pompeu Fabra } & $\begin{array}{l}\text { Fundamentos de la Historia y la Teoría } \\
\text { del arte }\end{array}$ & Optativa \\
\cline { 2 - 3 } & Arte contemporáneo & Optativa \\
\hline Universidad de Zaragoza & Corrientes artísticas contemporáneas & Optativa \\
\hline
\end{tabular}

Tabla 2. Asignaturas de Arte de los Grados en Periodismo en España.

Debido al ritmo frenético que exige la actualidad, se hace más necesario que nunca ofrecer a los lectores artículos que traten con rigor y de manera exhaustiva la información, en este caso, relativa al ecosistema artístico. No obstante, para que se pueda desarrollar un periodismo especializado de calidad es necesario despegarse de la inmediatez y disponer de tiempo para la reflexión para poder tratar en profundidad el tema. Las condiciones idóneas se darán, por tanto, en aquellos medios que tengan una periodicidad menor (semanal, mensual, etc.), como es el caso de los suplementos culturales y los programas de radio y televisión especializados en arte (o que tienen una sección dedicada al arte). Además, hay que tener en cuenta que a la hora de elaborar los contenidos será fundamental: «En primer término, la posesión de una cultura de carácter general suficientemente extensa y profunda, que permita identificar y correlacionar fenómenos, épocas, autores y obras significativas, tanto en el orden local como en el universal. En segundo lugar, una fuerte dosis de creatividad o, en su defecto, una buena capacidad para sistematizar y sintetizar procesos complejos en una apropiada fórmula comunicacional. En tercer término, un estilo formalmente correcto, fluido y atractivo, que demuestre en quien lo posee un apropiado dominio del idioma y de lo ensayístico periodístico». (Rivera 1995: 112)

Las tres cualidades citadas por Rivera son las que definirían el «perfil ideal» del periodista especializado en arte. Su papel no se debe confundir, aunque tenga aspectos en común, con el del crítico de arte. Para dejar claro cuáles son las diferencias que distinguen la función del crítico y la del periodista, nos remitimos a la siguiente cita de Rafael Llano (2016: 155): «El periodista escribirá, idealmente, solo sobre la cosa, del objeto, del acontecimiento, tratando de satisfacer las famosas cinco interro- 
gantes, que en inglés empiezan por 'w' (who, what, when, where, why). El crítico, en cambio, escribirá sobre sus impresiones, expresará sus opiniones críticas y hará recomendaciones». Aunque ambas figuras ejerzan de mediador entre el público y el ecosistema artístico, entre ellas existe una diferencia fundamental: el crítico tiene la misión de realizar una valoración, mientras que el periodista debe limitarse a proporcionarle información al lector, sin olvidar que «no es el objeto del periodismo expresar verdades absolutas sino contingentes, y expuestas siempre a la crítica y a la revisión» (Seijas 2003: 40).

Como es bien sabido, «el nivel de profundidad de la información que se maneje, así como de los códigos lingüísticos que se empleen, determinará el perfil de la audiencia a la que se pretende llegar» (Quesada 2012: 141). Aunque es cierto que a los lectores de este tipo de textos se les supone una cierta formación en la materia, el periodista debe ser consciente de que muchos de ellos no son expertos en arte y que «la descodificación lingüística, la interpretación del lenguaje y la divulgación de cara a los públicos es una tarea que corresponde al periodista» (Pérez Curiel 2005: 265). Por este motivo, es tan importante que el periodista que pretenda escribir sobre arte disponga, desde el inicio de la profesión, del vocabulario y la terminología propia de este campo para servir de guía al lector, y alcanzar la meta de todo periodismo especializado: la divulgación. Para ello, «el autor debe ofrecerle una serie de claves que sólo puede obtener a través del hecho documental» (Chacón y Jiménez 2001: 34), donde juegan un papel vital las fuentes. Como bien señala Concepción Pérez Curiel (2005: 265): «El estudio de las fuentes del periodismo especializado pone de manifiesto el uso de un vocabulario, de una terminología específica relacionada con el ámbito temático de cada sección». Y estas son las que vamos a tratar en el siguiente apartado.

\section{Fuentes para el periodismo especializado en arte}

Antes de escribir sobre cualquier temática, es preciso recopilar información de distintas fuentes que nos permitan contrastar los datos y elaborar un texto riguroso. Es muy importante que las que seleccionemos sean relevantes y fiables dentro del marco teórico en el que nos encontramos, en este caso, el cultural y, concretamente, el artístico. Sin embargo, como apunta Rodríguez Pastoriza, es cierto que «las fuentes de la información cultural están en la actualidad muy mediatizadas por dos grandes productores: las industrias culturales y las instituciones públicas y privadas» (2006: 41). Dentro del primer grupo, Pastoriza señala en el campo del arte: las galerías de arte y, como ejemplos del segundo grupo: los museos nacionales y los centros de arte y cultura oficiales, de ámbito público; y las fundaciones y las salas de exposiciones, de ámbito privado. En la práctica profesional es habitual que la primera toma de contacto del periodista, principiante o no, con el hecho noticioso sea a través de las notas de prensa que elaboran las agencias y los departamentos de comunicación de las citadas instituciones y organismos. Además, cuando los eventos son de especial importancia (por ejemplo, las inauguraciones de las exposiciones), celebran una rueda de prensa donde convocan a los periodistas para que los expertos y responsables del evento artístico les proporcionen la información de primera mano.

Sin embargo, el periodista no puede convertirse en un mero transcriptor del discurso de estas «fuentes interesadas», calificadas por Borrat (2003: 69) como «fuentes 
activas», que son las que toman la iniciativa de ponerse en contacto con el periodista. A la hora de elaborar sus textos es preciso que recurra también a las fuentes expertas porque «son las únicas que dominan el conocimiento experto necesario para elaborar una interpretación solvente de la realidad libre de valoraciones partidistas» (Quesada 2012: 56-57). Estas fuentes, pertenecen al grupo que Borrat (2003: 69) califica como «fuentes reactivas», ya que son consultadas por iniciativa del profesional. Este argumento no quiere decir que la información facilitada por los profesionales de comunicación sea errónea, pero hay que ser conscientes de que su principal función es la de publicitar y conseguir la máxima difusión posible del evento. Por tanto, están sujetas a estas «valoraciones partidistas» que mencionaba Quesada, y que se traducen en un lenguaje sobrecargado de adjetivos halagadores y en una sucesión de argumentos que prescinden por completo de señalar los puntos débiles o las carencias que puedan presentar los distintos elementos y agentes que intervienen en la exposición: la selección de las obras y de los artistas, el montaje, el comisariado, las cualidades espaciales o la financiación. Desgraciadamente, la poca distancia que muchos periodistas mantienen con estas fuentes es uno de los grandes problemas del periodismo especializado en arte. Por eso no es de extrañar que «la literatura académica haya denunciado desde hace décadas la servidumbre de los periodistas respecto a la iniciativa de fuentes interesadas y su falta de autonomía para decidir los temas y los enfoques de las noticias que precisa el ciudadano» (Rodríguez Rey et al. 2015: 88). Por este motivo, es fundamental que el periodista especializado en arte consulte tantas fuentes expertas como le sea posible.

Los estudios sobre la clasificación de las fuentes han sido abordados de manera minuciosa por varios de los autores ya citados, como Rafael Llano (2008) y Montserrat Quesada (2012). Sin embargo, en esta investigación, hemos utilizado los tres bloques en los que la profesora Elena Blanco Castilla divide las fuentes atendiendo a la tipología básica de su soporte: fuentes personales, fuentes documentales e internet. A continuación, hemos insertado dentro de estas tres categorías nuestra propia subdivisión de las fuentes.

4.1. Fuentes personales: son aquellas que «implican la relación directa del periodista con la persona que facilita la información, ya sea de manera directa o a través de terceros, tanto de forma accidental, esporádica o continuada» (Blanco 2015: 109). Las más importantes dentro del ámbito artístico son:

\subsubsection{Los artistas}

Son los autores de la obra y por tanto los que mejor la conocen y los que con más detalles nos la pueden describir a nivel técnico y procesual.

\subsubsection{Los galeristas}

Son los representantes de muchos artistas y en ocasiones llevan trabajando con ellos prácticamente desde el inicio de su carrera, factor que los convierte en grandes conocedores de su obra.

\subsubsection{Los comisarios}

Los comisarios son los encargados de organizar el discurso de la exposición y de decidir la selección y el montaje de las obras. Por lo tanto, son también grandes conocedores del trabajo de los artistas. 


\subsubsection{La propia experiencia}

Nuestra propia experiencia siempre será nuestra mejor aliada. Cuando se inaugura una exposición, es absolutamente necesario visitarla para poder realizar un buen texto que se aleje del discurso homogéneo de la nota de prensa y que marque la diferencia frente al resto de informaciones facilitadas por los otros medios.

4.2. Fuentes documentales: En esta sección se incluye «cualquier tipo de documento fiable que contenga datos útiles para responder a la demanda de información que pretende obtener el periodista, publicado en cualquier soporte, formato o medio físico: impresos, electrónicos o fotográficos» (Blanco 2004: 110). No obstante, no se hará referencia a los recursos fotográficos y audiovisuales. En su lugar los mencionaremos en el apartado 4.3. porque ya casi siempre se obtienen a través de internet.

4.2.1. Catálogos: Habitualmente las exposiciones cuentan con una publicación elaborada por un elenco de expertos, entre los que figura el comisario o los miembros del equipo curatorial. Aunque estos textos también proceden de una «fuente interesada» son sin duda mucho más rigurosos que las notas o los dosieres de prensa. Además, si la exposición es de un artista consolidado, con seguridad existirán también catálogos de otras exposiciones,que recomendamos consultar para tener una visión poliédrica y más completa de su carrera.

\subsubsection{Manuales y libros de Historia y Teoría del Arte}

Los libros escritos por expertos siempre serán una fuente fiable de consulta. Lo recomendable en estos casos es consultar el manual elaborado por el académico más relevante del tema sobre el que queramos escribir. La editorial Taschen cuenta con excelentes libros ilustrados sobre un gran número de artistas. Si por el contrario queremos estudiar un movimiento artístico, podemos recurrir a Los Manuales de Arte Cátedra, que son un referente en este campo. No obstante, es cierto que este tipo de libros pueden resultar demasiado densos para un periodista especializado que, la mayoría de las veces, busca una información rigurosa pero resumida. Para ello lo mejor es acudir a los manuales de Historia del Arte que están escritos, no solo para expertos en la materia, sino también para un público interesado, que además es el target del periodista especializado. Buenos ejemplos son: Historia del arte de E. H. Gombrich (Phaidon, 2013), Historia del Arte en la Antigüedad (Akal, 2011) de Johann Joachim Winckelmann o los cuatro volúmenes de Historia del Arte (Alianza Editorial) escritos por treinta y dos reputados especialistas bajo la coordinación de Juan Antonio Ramírez.

\subsubsection{Diccionarios de arte}

Los diccionarios de arte son indispensables para un periodista, ya que todos los textos de periodismo especializado en arte contienen tecnicismos propios de la disciplina. Aunque su significado se puede consultar en internet, sigue siendo muy útil tener a mano un diccionario que los englobe todos y que acompañe las definiciones con imágenes, como el Diccionario Visual de Términos de Arte coordinado por Lorenzo de la Plaza Escudero o el Diccionario Visual de Arquitectura de Frank Ching.

\subsubsection{Revistas especializadas y los suplementos culturales}

Las hemerotecas de las revistas especializadas y los suplementos culturales de referencia, tanto nacionales como extranjeros, están repletas de textos que sirven para 
tener una perspectiva histórica del acontecimiento artístico de la actualidad sobre el que queremos informar. En España, los suplementos culturales más importantes son El Cultural (El Mundo), Babelia (El País) y ABC Cultural. Dentro delas revistas destacan Lápiz, Descubrir el Arte y Exit, Imagen y Cultura, entre otras. Además, la mayoría de ellas se pueden adquirir también en su versión electrónica.

\subsubsection{Programas audiovisuales y radiofónicos especializados en arte}

Las hemerotecas de los programas de radio y televisión especializados en arte también son especialmente útiles, aunque lamentablemente en España contamos con muy pocos. Sin embargo, hay que destacar la gran labor en televisión del programa Metrópolis (RTVE) y, en radio, del programa Fluido rosa (RNE), que se han convertido en dos referentes dentro del mundo artístico.

\subsection{Internet}

Cuando el periodista recurre a esta categoría de fuente tiene que «dominar las estrategias de búsqueda y procesamiento de información en la red para convertirla en una fuente útil y amortizar el tiempo invertido» (Blanco 2004: 111). Recomendamos encarecidamente recurrir a internet para obtener los recursos fotográficos.

\subsubsection{Bancos de imágenes}

Alojan una amplia biblioteca de imágenes de obras que están clasificadas por categorías para su consulta. Algunas son de dominio público y se pueden descargar y utilizar libremente. Los bancos de imágenes de referencia son:

a) Wikiart (www.wikiart.org) es la enciclopedia de las artes visuales por excelencia a nivel internacional y está disponible en siete idiomas distintos, entre ellos el español. Cuenta con 250.000 imágenes de obras de arte que se acompañan de una ficha técnica. Las imágenes están clasificadas por artistas según movimientos artísticos, escuelas y grupos, géneros, áreas, nacionalidades, siglos e instituciones; y por obras de arte según el estilo, el género y el material empleado.

b) The Athenaeum (www.the-athenaeum.org) cuenta con un total de 341.668 imágenes de importantes obras de arte, con la ventaja de que 259.916 son de dominio público (sin Copyright). Las obras están clasificadas por distintas categorías: nombre del artista, movimiento artístico, museo y popularidad, entre otros. Todas las imágenes cuentan con una ficha técnica en la que se detalla el autor, el título de la obra, la fecha, el museo en el que se encuentra, las dimensiones y la técnica empleada. Eso sí la información solo está disponible en inglés.

c) VEGAP - Visual Entidad de Gestión de Artistas Plásticos- (bi.vegap.es) dispone de un catálogo de más de 60.000 imágenes de obras de arte contemporáneo. Sin embargo, aunque pueden consultarse en abierto, hay que pagar en caso de que se quiera hacer uso de ellas. VEGAP es una organización dedicada a gestionar y proteger los derechos de autor de los artistas conforme a la Ley de Propiedad Intelectual.

\subsubsection{Páginas web de los museos}

Los museos más importantes del mundo tienen disponible online la consulta de las obras de su colección (o de las más relevantes). A continuación, citamos tres de los museos más prestigiosos a nivel global, que destacan por tener un gran número de imágenes de obras en abierto. 
a) La web del Museo Metropolitano de Nueva York (www.metmuseum.org) cuenta con un inventario de 406.000 imágenes de dominio público, descargables en alta resolución. Se puede acceder a ellas por las categorías de artista y título, entre otras, y también se pueden buscar por filtros como el material, la fecha o el lugar de origen.

b) La web que comparten las TateGalleries - Tate Britain, Tate Modern, Tate Liverpool y Tate St. Ives- (www.tate.org.uk) dispone de un total de 79.189 imágenes de obras de arte.Además, la web también cuenta con un glosario con 463 términos de arte que pueden consultarse en cinco idiomas diferentes, entre ellos el español.

c) Para los periodistas que trabajen en España, será imprescindible la consulta de la web de la pinacoteca más importante de nuestro país, el Museo del Prado (www. museodelprado.es), con acceso a16.281 imágenes de obras que están documentadas con ficha técnica, una amplia descripción y un audio explicativo.

\subsubsection{Asociaciones artísticas}

Las páginas web de las asociaciones artísticas también ofrecen información sobre la actualidad del mundo del arte, elaborando informes o publicando noticias sobre acontecimientos relacionados con la asociación. Estas son muy útiles sobre todo para conseguir contactos. Ejemplos de webs accesibles y actualizadas son las de la Asociación Internacional de Críticos de Arte (AICA), Instituto de Arte Contemporáneo (IAC), Mujeres en las Artes Visuales (MAV) y Artistas Visuales Asociados de Madrid (AVAM).

4.3.4. Las páginas webs de los artistas o de las fundaciones dedicadas a difundir su trayectoria

Ofrecen información e imágenes sobre sus proyectos $\mathrm{y}$, además, son también un buen canal para contactar directamente con ellos o con los encargados de difundir su obra.

\section{Conclusiones}

La abundancia de informaciones que se elaboran a diario de manera casi instantánea en internet ha relegado a los pocos medios que todavía apuestan por el Periodismo Especializado a un nicho marginado profesionalmente. El periodista «especializado» cada vez es menos demandado y la tendencia es contar con periodistas «generalistas», incluso aunque el acontecimiento requiera de un periodista especializado. La precariedad laboral y la inmediatez de internet han hecho que el modelo de negocio avance en este rumbo en detrimento de la calidad y el rigor a la hora de tratar los contenidos.

Al mismo tiempo somos conscientes de que el acelerado ritmo que domina la práctica profesional y la labor «multitarea» que se ven obligados a asumir los periodistas no permite demasiado tiempo para la documentación. Aunque, por otra parte, este argumento nos sirve para reivindicar la necesidad de un estudio como este que incluya las claves del proceso de documentación del periodista especializado en arte para que pueda servirle de guía y de apoyo.

Esta investigación también ha desvelado que el espacio dedicado a la enseñanza del periodismo especializado en arte (que forma parte del área de Cultura de la asignatura de Periodismo Especializado o de la asignatura de Periodismo Cul- 
tural) es reducido y desigual dentro de los planes de estudio de las facultades de periodismo españolas. El Periodismo Especializado cuenta con una metodología que, por su complejidad, requiere ser explicada con detenimiento. Las facultades de periodismo no pueden, por ello, prescindir de una materia que es un pilar fundamental para transmitir la importancia del rigor, de la ética y del criterio a los jóvenes periodistas.

\section{Bibliografía}

Blanco, Elena: Emisores de mensajes informativos. Características, tipología y comportamiento de las fuentes especializadas, en J. Fernández del Moral (Coord.), Periodismo especializado. 1. edn. Barcelona, Editorial Ariel (Ariel Comunicación), 2004. ISBN: 84344130279788434413023

Borrat, Héctor: «Hacia una teoría de la especialización periodística». Anàlisi, 1993, 15, pp. 79-84. https://ddd.uab.cat/record/32861

Borrat, Héctor: «Las relaciones noticiables-Fuentes-Autores» en Esteve Ramírez, F. y Losada Vázquez, Á. El periodismo de fuente. Salamanca: Publicaciones Universidad Pontificia (Comunicación y pluralismo. Estudios de la Facultad de Comunicación, 4), 2003, pp. 65-84. ISBN: 84729955939788472995598

Chacón, Inmaculada y G. Jiménez, Antonio. «Documentación para el periodismo especializado», Revista General de Información y Documentación, 2001, 11 (2), pp. 33-60. https:// core.ac.uk/download/pdf/38822340.pdf

Fernández del Moral, Javier. «El periodismo especializado : un modelo sistémico para la difusión del conocimiento», en J. Fernández del Moral (Coord.), Periodismo especializado. 1. edn. Barcelona, Editorial Ariel (Ariel comunicación), 2004. ISBN: 8434413027 9788434413023

Fernández del Moral, Javier y Esteve Ramírez, Francisco: Fundamentos de la información periodística especializada. Madrid: Síntesis (Ciencias de la Información. Periodismo), 2010. ISBN: 84773821239788477382126

Llano, Rafael. «Periodismo cultural y Comunidad política. ¿De verdad deseamos saber?», 2016. https://www.nuevarevista.net/revista-artes/periodismo-cultural-y-comunidad-politica-de-verdad-deseamos-saber/

Llano, Rafael. La especialización periodística. Madrid: Técnos, 2008. ISBN: 9788430946846 8430946845

López, Xosé. «Información Cultural», en J. Fernández del Moral (Coord.), Periodismo especializado. 1. edn. Barcelona, Editorial Ariel (Ariel comunicación), 2004. ISBN: 84344130279788434413023

Pérez Curiel, Concha. Estudio de las Fuentes de Información en el marco del Periodismo Especializado : Estrategias de selección y tratamiento de las fuentes en las secciones periodísticas de El Mundo y El País. Tesis Doctoral. Universidad de Sevilla, Sevilla, 2005. https://idus.us.es/xmlui/handle/11441/24400

Quesada, Montserrat. Curso de periodismo especializado (Letras universitarias). Madrid (España), Editorial Síntesis, 2012. ISBN: 97884975680748497568079

Rivera, Jorge. B. El periodismo cultural. [1A ed.] edn. Buenos Aires, Paidós (Estudios de comunicación, 2), 1995. ISBN: 95012270229789501227024

Rodríguez Pastoriza, Francisco. Periodismo cultural. Madrid, Síntesis, 2006. ISBN: 8497563565 9788497563567 
Rodríguez Rey, Ana; Enguix González, Alicia; Rojas Torrijos, José Luís y García Gordillo, María del Mar. «La calidad de los medios y el uso de fuentes periodísticas en la prensa local de referencia en España», Estudios sobre el mensaje periodístico, 21 (Especial noviembre), 2015, pp. 85-100. http://revistas.ucm.es/index.php/ESMP/article/ view/50659/47057

Seijas Candelas, Leopoldo. Estructuras y fundamentos del periodismo especializado. Madrid, Editorial Universitas, 2003. ISBN: 84799115579788479911553 